Vol. 5, No. 1, 2019

Volodymyr Zelenyak ${ }^{1}$, Liubov Kolyasa ${ }^{2}$

${ }^{1}$ Department of Mathematics, Lviv Polytechnic National University, Ukraine, Lviv, S. Bandery Street, 12, ORCID 0000-0002-6653-4326, E-mail: volodymyr.zelenyak@gmail.com

${ }^{2}$ Department of Mathematics, Lviv Polytechnic National University, Ukraine, Lviv, S. Bandery Street, 12, ORCID 0000-0002-9690-8042, E-mail: kolyasa.lubov@gmail.com

\title{
MATHEMATICAL MODELING OF THE THERMOELASTIC STATE IN A CIRCULAR DISK WITH A CRACK DUE TO THE ACTION OF THE HEAT SOURCE
}

Received: April 13, 2019 / Revised: June 06, 2019 / Accepted: June 26, 2019

(C) Zelenyak V., Kolyasa L., 2019

Abstract. Purpose. To determine the two-dimensional thermoelastic state in a circular plate, weakened by an edge or internal crack induced by a stationary heat sourse. This paper proposes using singular integral equation (SIE) to investigate thermostressed intensity in the vicinity of the crack tip, depending on the local heat source placement and identify typical mechanical effects. Numerical results for the stress intensity factors (SIFs) can be potentially used to identify (with the limit equilibrium equations) critical values of the intensity of the local heat source at which crack begin to grow and the local destruction of the body. Methodology. The methods of studying twodimensional thermoelastic state body with crack as stress concentrators based on the function of complex variable method by which the problem of stationary thermoelasticity are reduced to a SIE of the first kind, a numerical solution which was obtained by the method of mechanical quadratures. Findings. In this paper graphic dependences of stress intensity factors at the crack tip on the relative position of crack and local heat source placement and on the length of crack are obtained. Originality. Scientific novelty lies in the fact that the solutions of the new two-dimensional problems of thermoelasticity for a circular plate containing a crack under the influence of local heating of heat source. Practical value. The practical value is the ability to more fully take into account the real situation in the thermoelastic elements of engineering structures with cracks that operate under conditions of heat stress in various industries, particularly in mechanical engineering. The results of specific values in the crack tip SIF in graphs may be useful in the development of sustainable modes of structural elements in terms of preventing the growth of cracks.

Keywords: crack, temperature stresses, heat source, stress intensity factor, singular integral equation.

\section{Introduction and literature review}

Elements of numerous engineering structures often work in conditions of thermal heating, which contribute to the appearance of their temperature stresses. This is typical for constructions in the heat energy industry. Their efficiency is largely determined by the level of concentration and intensity of these stresses in some areas, for example, in the vicinity of technological inhomogeneities (cracks, inclusion). In this case, the destruction of materials is associated with the presence of sharp stress concentrators such as a crack. Therefore, the study of the thermoelastic state near the crack is necessary for calculating the strength from the position of the mechanics of destruction, which is important for elements of structures of high strength and little plastic materials with a circular border, which are under the influence of different types of thermal loads.

A plate with a circular border (disk or plane with an aperture) and arbitrarily oriented thermally insulated cracks is investigated in [1]. In the paper [2], the thermal stresses in a circular disk with a 


\section{Volodymyr Zelenyak, Liubov Kolyasa}

rectilinear crack are determined due to the action of the heat source and the set temperature on the border of the disk. A similar problem in the case of arcuate cracks is solved in [3, 4]. In [5] a numerical solution of the problem of temperature stresses in a circular disk with a radial crack, which is under the action of an axisymmetric temperature field, is obtained. A circular disk with diameters cracks on the shores of which the temperature is given is considered in [6].

The method of singular integral equations solves the problems for determining the temperature stresses arising from the action of the heat source, located in a semi-infinite plate with an arbitrarily oriented edge crack, in articles [7, 8]. In the framework of plane deformation, the problem of quasi-static thermoelasticity for an unbounded hollow circular cylinder in the radial section of which is an internal or edge crack is considered in [9]. In [10], crack interaction and inclusion in a circular disk have been investigated. Local frictional heating of surface of a half-space containing a curvilinear crack in stationary state was investigated in the paper [11], and that with an inclusion and a crack was studied in [12].

\section{Circular disk with a central crack due to the action of the heat source}

Consider the circular disc of the radius $R_{0}$ containing the central crack. Let an arbitrary point of the disk on the $O x$ axis to the right of the crack placed a stationary source of heat power $q$. We suppose that the shores of the crack are not in contact, unloaded, thermally insulated (as well as the lateral surfaces of the disk), and on the circular border of the disk the temperature is set, as well as no load (Fig. 1). Under these conditions, there is no heat flux through the crack shores. Then, based on the principle of linearity, the complete solution of the thermoelasticity problem for a given domain is obtained by superpositioning the following problems:

Problem A - to determine the thermoelastic state of a homogeneous disk without a crack due to the point stationary source of heat power $q$ and to find components of stress on the line of the crack;

Problem B - to solve the elastic problem for a homogeneous disc with a crack, assuming that the stresses, equal in magnitude and opposite to those found in the previous problem A on the segment of the crack location, are applied to the shores of the crack.

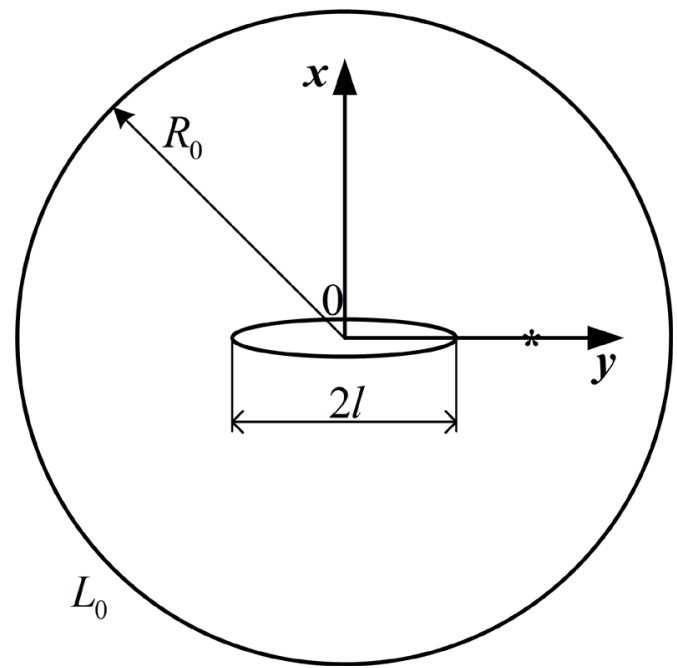

Fig. 1. Circular disk with a central crack under the action of a heat source

Consider solving the above tasks.

Problem A. The temperature stresses from the heat source placed on the $O x$ axis in a homogeneous disc without a crack in relative polar coordinates $(\rho, \theta)$ with a pole in the center of the disk is written in the form [13]

$$
\frac{\sigma_{\theta}}{K}=2 \ln \frac{\rho_{1}}{\rho_{2}}+\frac{4\left(1-\rho_{0}^{2}\right)}{\rho_{2}^{2}}\left(1-\rho \rho_{0} \cos \left(\theta-\theta_{0}\right)-0,5 \rho_{2}^{2}\right)-
$$


Mathematical Modeling of the Thermoelastic State in a Circular Disk with a Crack ...

$$
-\frac{\left(1-\rho_{0}^{2}\right)\left(1-\rho^{2}\right)}{\rho_{1}^{2} \rho_{2}^{4}}\left(\rho_{0}^{2}\left(\rho_{1}^{2}-\rho_{2}^{2}\right)\left(\cos \left(\theta-\theta_{0}\right)-1\right)+\rho_{0}^{2} \rho_{1}^{2} \rho_{2}^{2}\right) ; \quad \tau_{\rho \theta}=0
$$

where $\rho_{1}^{2}=\rho^{2}+\rho_{0}^{2}-2 \rho \rho_{0} \cos \left(\theta-\theta_{0}\right) ; \rho_{2}^{2}=1+\rho^{2}+\rho_{0}^{2}-2 \rho \rho_{0} \cos \left(\theta-\theta_{0}\right) ; \rho=r / R_{0} ; \rho_{0}=r_{0} / R_{0}$; $\rho_{0}, \theta_{0}$ are coordinates of the source of heat; $K=\frac{q}{4 \pi \lambda} k ; \lambda$ is coefficient of thermal conductivity; $k=\alpha^{t} E-$ for a plane stressed state; $\alpha^{t}$ is temperature coefficient of linear expansion; $\sigma_{\theta}, \tau_{\rho \theta}$ are normal and tangent stress components, respectively.

Problem B. Consider a circular disc of a radius $R_{0}$ mapped to a coordinate system $x O y$ with a start in the center of the disk, on the $|x|<l$ axis $O x$ of which there is a crack. The disk contour is unloaded, on the shores of the crack given normal stress components, which are defined earlier in problem A. Then we find the distribution of stresses in the disk from the solution of the integral equation, which in the dimensionless coordinates has the form [14]

$$
\int_{-1}^{1}\left[R(\xi, \eta) g^{\prime}(\xi)+S(\xi, \eta) \overline{g^{\prime}(\xi)}\right] d \xi=\pi P(\eta), \quad|\eta|<1,
$$

where

$$
\begin{gathered}
R(\xi, \eta)=\frac{1}{\xi-\eta}+\frac{\varepsilon^{2}}{2(1-\varepsilon \xi \eta)^{3}}\left[4 \eta-5 \xi+\varepsilon^{2} \xi\left(\xi \eta+3 \xi^{2}-3 \eta^{2}\right)+\varepsilon^{4} \eta \xi^{2}\left(\xi \eta+\eta^{2}-\xi^{2}\right)+\varepsilon^{6} \xi^{4} \eta^{3}\right] \\
S(\xi, \eta)=\frac{\varepsilon^{2}}{2\left(1-\varepsilon^{2} \xi \eta\right)^{2}}\left[2 \eta-\xi+\varepsilon^{2} \xi\left(\xi^{2}-2 \xi \eta-\eta^{2}\right)+\varepsilon^{4} \xi^{3} \eta^{2}\right]
\end{gathered}
$$

$\varepsilon=l / R ; P(\eta)=\sigma(\eta)+i \tau(\eta) ; \sigma(\eta), \tau(\eta)$ are normal and tangential stresses on the shores of the crack, defined in (1) and taken with the opposite sign $\left(\sigma(\eta)=-\sigma_{\theta}, \tau(\eta)=-\tau \rho \theta\right) ; g^{\prime}(\xi)$ is derived from the jump of displacements on the contour of the crack.

The solution of equation (2) must satisfy the condition

$$
\int_{-1}^{1} g^{\prime}(\xi) d \xi=0
$$

which ensures the uniqueness of the displacements bypassing the contour of the crack. The stress intensity factors (SIFs) in the vicinity of the crack tips are found by the formula [14]

$$
K_{I}^{ \pm}-K_{I I}^{ \pm}= \pm \lim _{t \rightarrow l^{+}} g^{\prime}(t) \sqrt{2 \pi\left|t-l^{ \pm}\right|} .
$$

In formula (4), SIFs $K_{I}^{ \pm}, K_{I I}{ }^{ \pm}$are real quantities that characterize the stress-strain state in the vicinity of the crack tips.

The numerical solution of the system of equations (2), (3) is obtained by the method of mechanical quadratures [14], when the heat source is at a distance of $\rho_{0}=0.9$ from the center of the crack. Graphs for dimensionless stress intensity factors $K_{I} / K_{q}\left(K_{I I} / K_{q}=0\right.$ since $\left.\tau_{\rho \theta}=0\right)$, where $K_{q}=K \sqrt{l}$ is shown in Fig. 2. Dashed lines (right top of the crack correspond to the $K_{I}^{+} / K_{q}$ ), dashed punctuation ( left top of the crack correspond to the $\left.K_{I}^{-} / K_{q}\right)$ refer to the case when a one source of heat is to right $\left(\theta_{0}=0\right)$ of the center of the disk. The solid curve refer to the case when two heat sources equidistant from the center of the disk $\left(K_{I}^{-} / K_{q}=K_{I}^{+} / K_{q}\right)$ are function. 


\section{Volodymyr Zelenyak, Liubov Kolyasa}

As can be seen from Fig. 2, approximation of the right top of the crack to the heat source leads to a decrease in the values of the SIFs to the negative values (there is a contact of the shores of the crack, which is not considered in this model), and the removal of the left top leads to a slight increase.

\section{Circular disk with an edge crack due to the action of the heat source}

Let's start the Cartesian coordinate system $x O y$ at the edge of the circular disc of the radius $R_{0}$, pointing the axis $O x$ along the diameter (Fig. 3). The disk is weakened by an edge crack in length $l$, which extends from the origin of the coordinates along the axis $O x$.

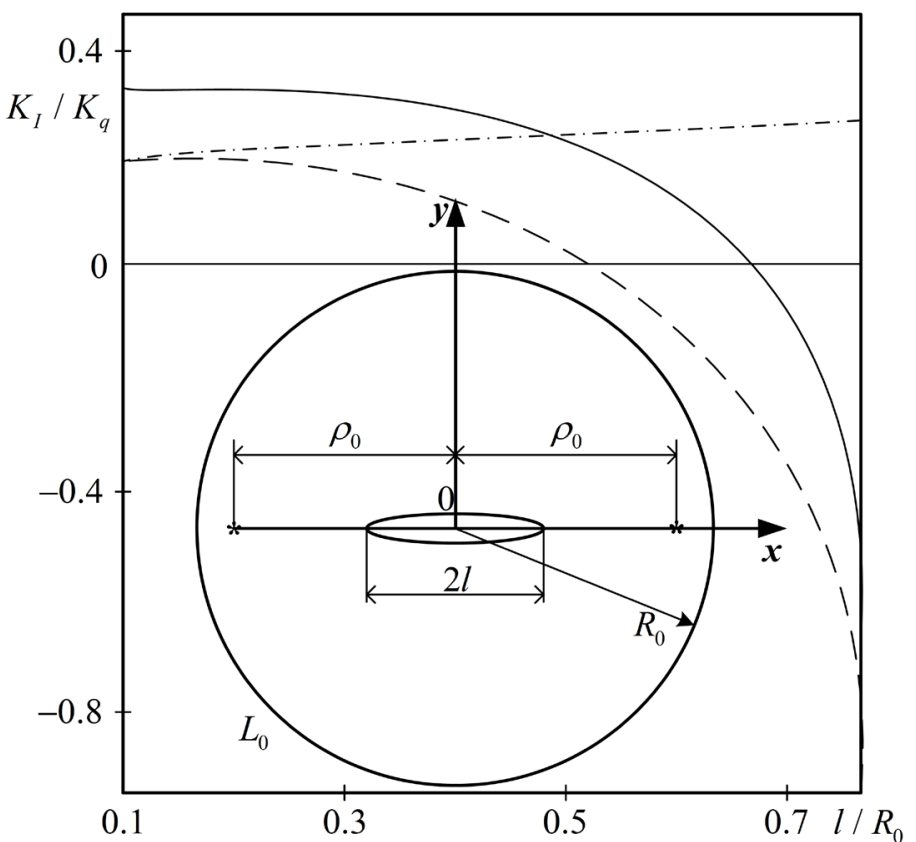

Fig. 2. Dependence of SIF $K_{I} / K_{q}$ on the length of the crack for a fixed position of the source of heat

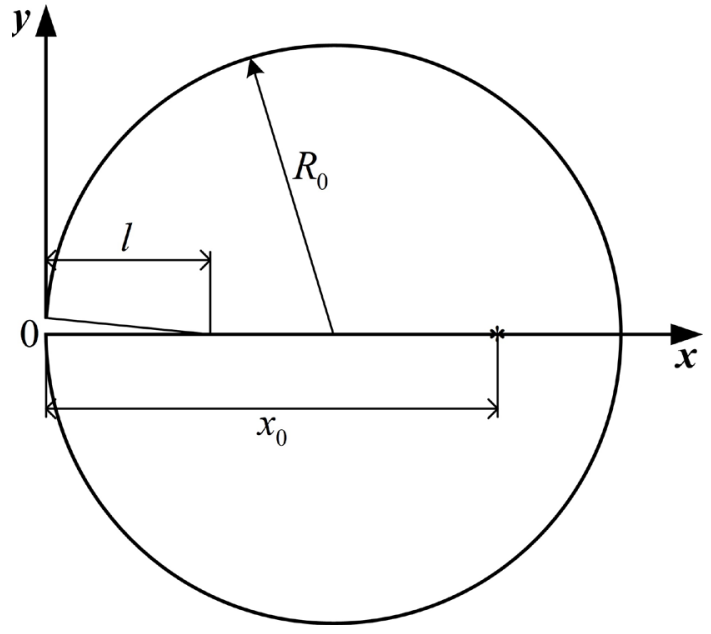

Fig. 3. Geometry of a circular disk with an edge crack and placed in it by a source of heat

At the point $M_{0}\left(x_{o}, 0\right)$ of the axis $O x\left(x_{0}>l\right)$ there is a point source of heat of constant power $q$. We suppose that the shores of the crack are not in contact, unloaded, thermally insulated (as well as the lateral surfaces of the disk), and the temperature of the disk is set on the circular border, as well as no load. Under these conditions, there is no heat flux through the crack shores and the solution to the problem of the thermoelastic state of a disk can be obtained as a superposition of two problems: 1) the problem of the thermoelastic state of a solid disk without a crack due to the point source of heat;2) the elastic problem for a disk with a crack, to the shores of which are enclosed with the opposite sign of stress, obtained in the first problem on the segment of the location of the crack. Since the solution, the first problem is known (see formula (1)), then consider the second problem, using the technique developed in [15].

Integral equation for elastic problem in dimensionless variables, has the form [14]:

$$
\int_{0}^{1}\left[R(\varepsilon, \eta) g^{\prime}(\xi)+S(\xi, \eta) \overline{g^{\prime}(\xi)}\right] d \xi=\pi P(\eta), \quad 0<\eta<1,
$$

where

$$
\begin{aligned}
& R(\xi, \eta)=\frac{1}{\xi-\eta}+\frac{1}{2(\xi+\eta-\varepsilon \xi \eta)^{3}}+\left[2\left(\eta^{2}+4 \xi \eta-\xi^{2}\right)-\right. \\
& -2 \varepsilon \xi\left(3 \eta^{2}+7 \xi \eta+2 \xi^{2}\right)+2 \varepsilon^{2} \xi\left(\eta^{3}+6 \eta^{2} \xi+7 \eta \xi^{2}+\xi^{3}\right)- \\
& \left.-\varepsilon^{3} \xi^{2} \eta\left(5 \eta^{2}+11 \xi \eta+4 \xi^{2}\right)+\varepsilon^{4} \xi^{3} \eta^{2}(4 \eta+3 \xi)-\varepsilon^{5} \xi^{4} \eta^{3}\right]
\end{aligned}
$$


Mathematical Modeling of the Thermoelastic State in a Circular Disk with a Crack ...

$$
\begin{gathered}
S(\xi, \eta)=\frac{\varepsilon \xi}{2(\xi+\eta-\varepsilon \xi \eta)^{2}-\eta}\left[-4 \xi+2 \varepsilon(\xi+\eta)^{2}-\varepsilon^{2} \xi \eta(3 \eta+3 \xi)+\varepsilon^{2} \eta^{2} \xi^{2}\right] ; \\
\varepsilon=l / R ; \quad P(\eta)=\sigma(\eta)+i \tau(\eta) ;
\end{gathered}
$$

$\sigma(\eta), \tau(\eta)$ are normal and tangential stresses on the shores of the crack, defined in (1) and taken with the opposite $\left.\left(\sigma(\eta)=-\sigma_{\theta}, \tau(\eta)=-\tau_{\tau \theta}\right)\right) ; g^{\prime}(\xi)$ is derived from the jump of displacements on the contour of the crack.

After replacing the variables, transform the equation (5) into a form

$$
\int_{-1}^{1}\left[R_{1}\left(\xi_{1}, \eta_{1}\right) g_{1}\left(\xi_{1}\right)+S_{1}\left(\xi_{1}, \eta_{1}\right) \overline{g_{1}\left(\xi_{1}\right)}\right] d \xi_{1}=\pi P_{1}\left(\eta_{1}\right), \quad\left|\eta_{1}\right|<1
$$

where

$$
\begin{gathered}
R_{1}\left(\xi_{1}, \eta_{1}\right)=\frac{1}{2} R\left(\left(\xi_{1}+1\right) / 2,\left(\eta_{1}+1\right) / 2\right) ; \\
S_{1}\left(\xi_{1}, \eta_{1}\right)=\frac{1}{2} S\left(\left(\xi_{1}+1\right) / 2,\left(\eta_{1}+1\right) / 2\right) ; \\
P_{1}\left(\xi_{1}\right)=P\left(\left(\eta_{1}+1\right) / 2\right), \\
g^{\prime}{ }_{1}\left(\xi_{1}\right)=g^{\prime}\left(\frac{\xi_{1}+1}{2}\right) .
\end{gathered}
$$

We will submit the function $g^{\prime}{ }_{1}\left(\xi_{1}\right)$ in the form $g_{1}^{\prime}\left(\xi_{1}\right)=\frac{U\left(\xi_{1}\right)}{\sqrt{1-\xi_{1}^{2}}},\left|\xi_{1}\right|<1$, and define $U\left(\xi_{1}\right)$ in the form of an interpolation polynomial of Lagrange in the nodes of Chebyshov

$$
\xi_{1}^{K}=\cos \left(\frac{2 k-1}{2 n} \pi\right), \quad(k=1,2, \ldots, n) .
$$

Instead of condition (3) known for internal cracks, use the relation

$$
U_{1}(-1)=0
$$

which indicates that the function corresponding to the top of the crack, which extends to the edge of the disk, has a feature smaller than that of. Using the Gauss quadrature formulas for singular and regular integrals [14], we obtain from the equation (6) and condition (7) a system of linear algebraic equations for the determination of $n$ unknowns $U\left(\xi_{1}^{k}\right)$

$$
\begin{gathered}
\frac{1}{n} \sum_{k=1}^{n}\left[K_{1}\left(\xi_{1}^{k}, \eta_{1}^{m}\right) U\left(\xi_{1}^{k}\right)+L_{1}\left(\xi_{1}^{k}, \eta_{1}^{m}\right) \overline{U\left(\xi_{1}^{k}\right)}\right]=P_{1}\left(\eta_{1}^{m}\right),(m=1,2, \ldots, n-1) ; \\
\sum_{k=1}^{n}(-1)^{k} U\left(\xi_{1}^{k}\right) \operatorname{tg}\left(\frac{2 k-1}{4 n} \pi\right)=0, \quad \eta_{1}^{m}=\cos \frac{\pi m}{n} .
\end{gathered}
$$

The stress intensity factors (SIFs) in the vicinity of the crack tip are found by the formula [14]

$$
K_{I}-i K_{I I}=\sqrt{\frac{l}{2}} \frac{1}{n} \sum_{k=1}^{n}(-1)^{k+1} U\left(\xi_{1}^{k}\right) \operatorname{ctg}\left(\frac{2 k-1}{4 n} \pi\right) .
$$

The numerical solution of the singular integral equation (6) is obtained by the method of mechanical quadratures. Graphs for dimensionless stress intensity factors $K_{I} / K_{q}\left(K_{I I} / K_{q}=0\right.$ since $\left.\tau_{\rho \theta}=0\right)$, where $K_{q}=K \sqrt{l}$ is shown in Figs. 4 and 5.

An analysis of numerical results showed: when the source approaches the line of the crack to its top, SIF $K_{I} / K_{q}$ is initially increased, reaching a certain maximum, and at the very top it decreases (Fig. 4). If 


\section{Volodymyr Zelenyak, Liubov Kolyasa}

the heat source is located to the right of the center of the disk, then with increasing length of the crack the SIF $K_{I} / K_{q}$ increases; if on the left - the SIF decreases (Fig. 5).

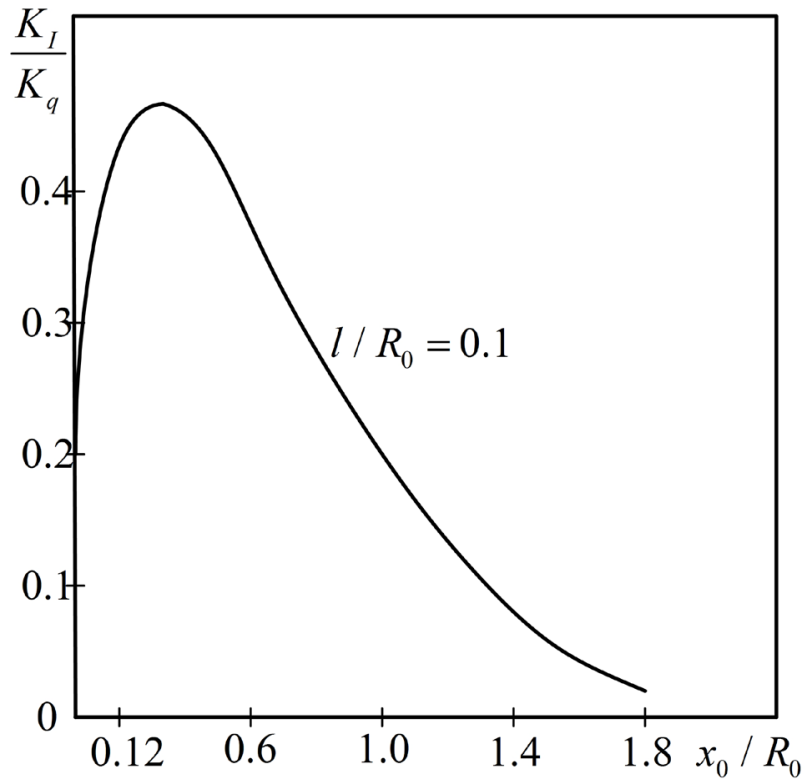

Fig. 4. Dependence of SIF $K_{I} / K_{q}$ on the distance between heat source and top of the crack with fixed length

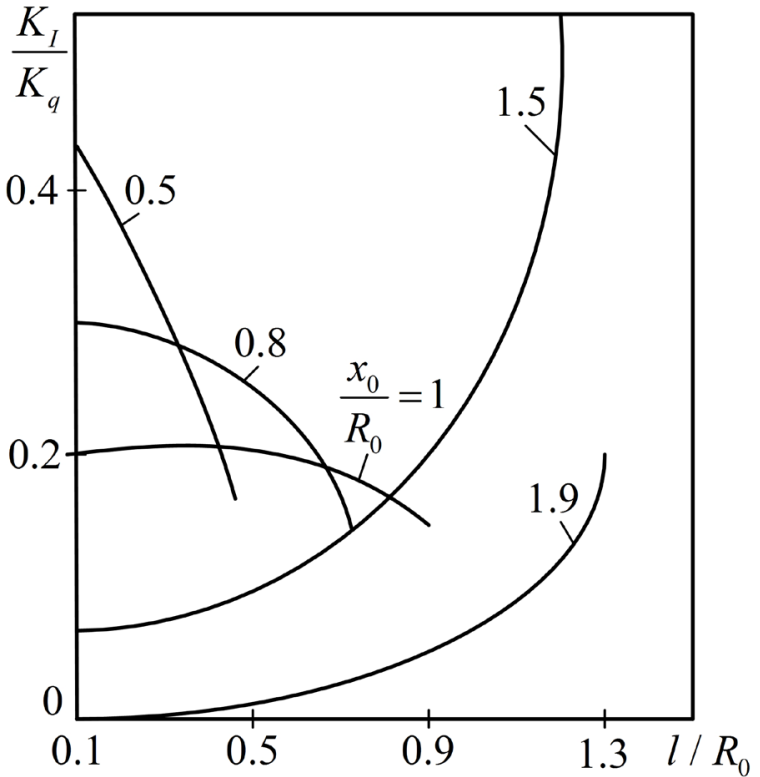

Fig. 5. Dependence of SIF $K_{I} / K_{q}$ on growth cracks for the fixed location of the heat source

In the considered model, we suppose that the shores of the crack are not contacted. Then, according to the criterion (based on the hypothesis about the initial growth of the crack) from equations of the boundary equilibrium [15] it is possible to draw conclusions about the critical values of the power of the heat source, in which the growth of the crack begins and the local destruction of the body, according to the formula $q_{\kappa p}=\frac{\lambda}{\alpha_{t} E \sqrt{\pi l}} \cdot \frac{K_{1 C}}{K}$, where $K_{1 C}$ is the material constant, which characterizes the resistance of the material to the destruction and is determined experimentally, $K=K_{I} / K_{q}$.

\section{Conclusions}

If the heat source is to the left of the centre of the disk, the critical value of the power of the heat source increases with the growth of the crack and, conversely, decreases if the heat source is to the right of the disk centre (Fig. 5). For a fixed crack length, the approach of the source of heat to the crack initially leads to a decrease in the critical value, and near the top of the crack, to increase (Fig. 4).

The practical value of the obtained results is the possibility of more fully taking into account the real thermoelastic state in elements of engineering structures with cracks that operate under thermal stresses. The results of specific values of the stress intensity factors at the top of the crack in the form of charts may be useful in developing rational modes of operation of elements of structures in terms of preventing the growth of cracks.

\section{References}

[1] I. F. Soltys, "Temperaturnyye napryazheniya $\mathrm{v}$ uprugoy ploskosti $\mathrm{s}$ krugovoy granitsey i termoizolirovannymi treshchinami zumovleni dzherelom tepla" ["The thermal elasticity of a circular plate with arcshaped cracks due to the source of heat"], Fizico-khimicheskaia mekhanika materialov [Physicochemical mechanics of materials], no. 1, pp. 94-98, 1978. [in Russian].

[2] N. A. Dorosh, and G. S. Kit, "Temperaturni napruzhennya v kruhliy plastyni z trishchynoyu, zumovleni dzherelom tepla" ["Temperature stresses in a plate with a crack due to a source of heat"], Visnyk Lvivskoho Politehnichnoho Instytutu [Bulletin of Lviv Polytechnic Institute], no. 31, pp. 58-64, 1969. [in Ukrainian]. 


\section{Mathematical Modeling of the Thermoelastic State in a Circular Disk with a Crack ...}

[3] N. A. Dorosh, "Termouprugost' krugloy plastiny s dugoobraznoy treshchinoy, obuslovlennaya istochnikom tepla" ["Thermoelasticity of a circular plate with an arched crack caused by a source of heat"], Vestnik Lvovskogo Politekhnicheskogo instituta [Bulletin of Lviv Polytechnic Institute], no. 25, pp. 200-204, 1968. [in Russian].

[4] N. A. Dorosh,. "Termouprugost' krugloy plastiny s dugoobraznymi treshchinami, obuslovlennaya istochnikom tepla" ["The thermal elasticity of a circular plate with arc-shaped cracks due to the source of heat"], Vestnik L'vovskogo Politekhnicheskogo instituta [Bulletin of Lviv Polytechnic Institute], no. 47, pp. 176-180, 1970. [in Russian].

[5] L. N. Karpenko, "O razvitii treshchiny v kruglom nagrevayemom diske" ["On the development of a crack in a circular heated disk"], Problemy prochnosti [Strength problems], no. 3, pp. 51-53, 1974. [in Russian].

[6] G. S. Kit, "Napryazhennoye sostoyaniye kruglogo diska s treshchinami, na beregakh kotorykh zadany temperatura ili teplovoy potok" ["The stressed state of a circular disk with cracks on which the temperature or heat flow is given"], Matematicheskiye metody i fiziko.-mekhanicheskiye polya [Mathematical methods and physicomechanical fields], no. 7, pp. 102-107, 1978. [in Russian].

[7] V. M. Zelenyak, “Temperaturni napruzhennya u napivneskinchenniy plastyni z dovil'no oriyentovanoyu krayovoyu trishchynoyu, zumovleni dzherelom tepla" ["Thermal stresses in a semi-infinite plate with an arbitrarily oriented edge cracks caused by a source of heat"], Prykladni problemy mekhaniky i matematyky ["Applied problems of mechanics and mathematics"], no. 13, pp. 117-121, 2015. [in Ukrainian].

[8] S. Ya. Matusyak, A. A. Evtushenko, and V. M. Zelenyak, "Termouprugoye sostoyaniye polubeskonechnoy plastinki s krayevoy treshchinoy, obuslovlennoye istochnikom tepla" ["The thermoelastic state of a semi-infinite plate with an edge crack due to the source of heat.], Inzhenerno-fizicheskiy zhurnal [Journal of engineering physics and thermophisics], vol. 7, no. 2, pp. 134-137, 2003. [in Russian].

[9] F. Delale, and S. P. Kolluri, "Fracture of thick-walled cylinders subjected to transient thermal stresses", $J$. Therm. Stresses, vol. 8, issue 2, pp. 245-248, 1985.

[10] V. M. Zelenyak, "Termopruzhna vzayemodiya trishchyny ta vklyuchennya u kruhovomu dysku" ["Thermo-elastic interaction of a crack and inclusion in a circular disk"], Fizyko-matematychne modelyuvannya ta informatsiyni tekhnolohiyi [Phicico-mathematical modeling and informational technologies], no. 21, pp. 109-116, 2015. [in Ukrainian].

[11] V. M. Zelenyak, and L. I. Kolyasa, "Thermoelastic state of a half plane with curvilinear crack under the conditions of local heating", Materials Science, vol. 52, issue 3, pp. 315-322, 2016.

[12] V. M. Zelenyak, "Investigation of the thermoelastic state of two-dimensional composite bodies with cracks", Materials Science, vol. 50, issue 1, pp. 14-19, 2014.

[13] D. V. Grilytsky, and I. M. Osiv, Zadachi teploprovidnosti i termopruzhnosti dlya plastyn [Problems of thermal conductivity and thermoelasticity for plates]. Lviv, Ukraine: Vydavnytstvo Lvivskoho universytetu Publ., 1974. [in Ukrainian].

[14] M. P. Savruk, Dvumernye zadachi uprugosti dlya tel s treshchinami [Two-dimensional elasticity problems for bodies with cracks]. Kyiv, Ukraine: Naukova dumka Publ., 1981. [in Russian].

[15] V. V. Panasyuk, M. P. Savruk, and A. P. Datsyshin, Raspredelenie napryazheniy okolo treshchin v plastinah i obolochkah [Distribution of stresses near cracks in plates and shells]. Kyiv, Ukraine: Naukova dumka Publ., 1976. [in Russian]. 